\title{
"Something in the Way She Moves"- Metaphors of Musical Motion
}

\author{
Mark L. Johnson \\ Department of Philosophy \\ University of Oregon \\ Steve Larson \\ School of Music \\ University of Oregon
}

\begin{abstract}
Our most fundamental concepts of musical motion and space, used by laypeople and music theorists alike, are defined by conceptual metaphors that are based on our experience of physical motion. We analyze the 3 most important metaphors of musical motion: the "MOVING MUSIC" metaphor, the "MUSICAL LANDSCAPE" metaphor, and the "MOVING FORCE" metaphor. We show how each metaphor is grounded in a particular basic experience of physical motion and physical forces and how the logic of physical motion shapes the logic of musical motion. We suggest that our conceptualization of, discourse about, and even our experience of musical motion depend on the logic of these 3 metaphors.
\end{abstract}

Music moves. And something in the way it moves moves us. The relative ease with which we talk about musical motion might fool us into thinking that we know quite well what musical motion is. But do we? This article suggests how the "theory of conceptual metaphor" that has developed over the past two decades can explain important aspects of our experience and understanding of musical motion. As we will see, the logic of certain metaphors shapes our understanding of musical motion and constrains the inferences we make in reasoning about such motion. These metaphors define what moves, the way it can move, and where it moves to.

Using the tools and analytic resources of the theory of conceptual metaphor, we argue for two major claims: (a) our understanding of musical motion is entirely

Requests for reprints should be sent to Mark L. Johnson, Department of Philosophy, 1295 University of Oregon, Eugene, OR 97403-1295. E-mail: markj@oregon.uoregon.edu 
metaphoric, and (b) the key metaphors are grounded in three of our basic bodily experiences of physical motion.

Writers such as Bonds (1992), Coker (1972), Ferguson (1960), and Marion (1981, 1991) have written with great insight on the central role of metaphor in music. Others, including Aksnes (1997, 2001), Bauer (in press), Brower (1997-1998, 2000), Larson (1997, 1997-1998, 1999, 2002), Mead (1997-1998), O'Donnell (1999), Saslaw (1996, 1997-1998), Walsh (Saslaw \& Waish, 1996), and Zbikowski $(1997,1997-1998,1998)$, have explicitly used the theory of conceptual metaphor to illuminate the theory and analysis of music. Still others have focused on the embodied nature of musical meaning, including Cusick (1994), Graybill (1990), McClary (1991), Mead (1999), and Pierce (1989).

Our analysis focuses exclusively on the ways we utilize body-based conceptual metaphors to comprehend and reason about musical motion within "common-practice tonal music" (the western-European music of Bach to Brahms and some contemporary jazz and popular music). ${ }^{1}$ It is a live empirical issue--one that can be settled only by future historical and cultural research-how metaphors grounded on apparently universal aspects of bodily functioning might still give rise to cultural differences in the understanding of music, differences based on differing cuitural values, interests, and practices.

\section{WHAT IS MUSICAL MOTION?}

If we try to explain how the opening line of the Beatles" "Something" (Harrison, 1969) captures the meaning and sound of the words "Something in the way she moves," we immediately encounter two metaphorical senses of motion, one related to pitch and the other to rhythm. First, the pitches move. Before the word "moves," every note is sung to the same pitch. When we reach "moves," the pitch "moves" (down from C to B). Second, the rhythm "moves." It "moves" in the same way that speech rhythms do, so that accented words are musically accented. Moreover, the words that are the most important to the song's message ("something," "way," and "moves") are emphasized through agogic and metric accents. To better appreciate this, consider the musical notation given in Figure 1. If one sings each of the words with notes of equal duration, as in Figure 1a, the result is stiff, unmusical, and at odds with the rhythms and accents of speech-it does not "flow." Putting the main words on the main beats, as in Figure $1 \mathrm{~b}$, is an improvement, because it produces a more speech-like prosody. But the Beatles' setting,

\footnotetext{
'Within those traditions, the idea of musical motion has been discussed for centuries. (See, for example, Rothfarb's, 2001, history of references to musical motion.) Moreover, the idea of musical motion appears to be common to musical cultures around the globe. Scholars such as Feld (1981) have shown how the theory of conceptual metaphor can illuminate aspects of music of other cultures.
} 


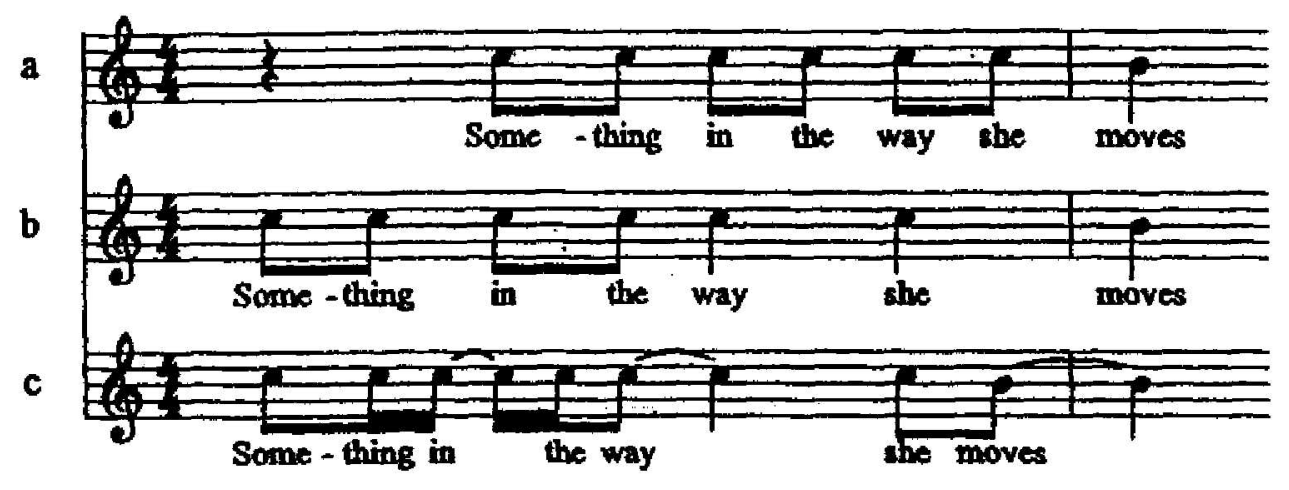

FIGURE 1 George Harrison, "Something," opening lyric compared to two alternate settings..

Figure 1c, is even better. Each of these three notes receives a different kind of accent, and those differences create an overall shape that leads to the word "moves" ("Some-" is a downbeat. "Way" is an anticipated long note. And "moves" is both, which gives it special emphasis). To appreciate the "motion quality" of this overall shape, sing this melody and stop "up in the air" on the word "way." Suspended on the long note "way," we feel a strong anticipation of movement to the next downbeat ("moves"), to complete both the musical and semantic sense of the passage.

In these ways, the music reflects the meaning of the words. But notice that the musical meaning does not depend on the words. Even without the lyrics, we would still speak of the melody "moving" from $\mathrm{C}$ to $\mathrm{B}$, or of the rhythm "moving" ahead.

This one brief musical passage is enough to suggest two of the many senses of musical motion that we use all the time to think and to talk about our musical experience. But, although our discourse about music is filled with such references to motion, the idea of musical motion is a profound enigma. In a section entitled "The Paradox of Tonal Motion,"Zuckerkandl (1969) reminded us that we know almost nothing about melodic motion. He surveyed a number of received ideas we have about tonal motion and then showed that they appear to have little to do with our ordinary literal understanding of motion. A typical passage conveys just one of the many enigmas of melodic motion. Zuckerkandl asked whether tones move, then answered

Actually, they stand still! In the Marsellaise, for example, we hear the first tone E-it does not move; then comes A, another static tone; this one is repeated; then comes B; and so on. No tone, as long as it sounds, moves from its place. What has happened to the motion? ... Motion is the process that conveys the thing from here to there, in a continuous and never suspended traversal of the interval. If it stops anywhere, the motion is instantly abolished. But in a melody we have nothing but this, nothing but stops, a stringing together of static tones, and, between tone and tone, no connection, no transition, no filling up of intervals, nothing. It is the exact opposite of motion. (p. 83) 
Many writers (such as Ferguson, 1960, and Davies, 1994) have tried to address the problem of musical motion, but we still lack a clear answer to the question posed by Zuckerkandl.

So the concepts of musical motion that all of us use unreflectively to describe our musical experience turn out, under scrutiny, to be anything but clear, literal, and unproblematic. Musical motion must be some kind of metaphorical motion that takes place within a metaphorical space. Our project here is to explain the metaphoric structure and logic of such motion and to ask what this means for how we experience and understand music. Just as the Beatles emphasize, in turn, different words in the lyric "Something in the way she moves," we have begun with the observation that something in the music "moves"; we next consider the question of what the something is that moves, and then go on to look at the way music "moves."

\section{CONCEPTUAL METAPHOR AND TEMPORAL MOTION}

To analyze our metaphorical concepts of tonal motion, we must first understand our concepts of time, all of which are profoundly metaphoric. We typically conceptualize the "passing" of time metaphorically - as motion through space. Morgan (1980) noted the inseparability of musical space and musical time, and Alperson (1980) noted that our experience of musical motion depends on "the familiar habit of regarding the properties of time as analogous to those of space" (p. 409). Alperson cites Bergson's claim that

we set our states of consciousness side by side in such a way as to perceive them simultaneously, no longer in one another, but alongside one another; in a word we project time into space, we express duration in terms of extensity, and succession thus takes the form of a continuous line or chain, the parts of which touch without penetrating one another. (p. 409)

Recent research in cognitive linguistics has revealed the marvelously complicated internal structure of such Western metaphorical conceptions of time, and it explains how we reason about time based on these inescapable, yet mostly invisible, metaphors. ${ }^{2}$ What this research shows is that there are two basic spatialization metaphors for time, and, as we shall see, each has a relevant counterpart in our conception of musical time and motion.

Consider, first, how we are conceptualizing time when we speak of it as "flying," "dragging," and "rushing by us," and when we say things like "Easter will soon be here" and "Christmas has long since passed." Here we understand temporal change as a particular kind of motion through space. There is a spatial schema

\footnotetext{
${ }^{2}$ The following abbreviated analysis of spatial metaphors for time is based on a larger analysis found in Lakoff and Johnson (1999).
} 
in which an observer is facing in a fixed direction ("facing the future"), is situated at "the present" (the "here and now"), and times are conceptualized as objects moving toward and then past the stationary observer. Elements and structures of this spatial schema are mapped onto our understanding of time to form the "MOVING TIMES" metaphor. In the diagram of this mapping shown in Table 1, spatial motion is the "source domain" from which structure and relations are projected (as indicated by the direction of the arrow) onto the "target domain" (here, temporal change) that we are understanding via the mapping.

Notice the tight internal logic of this metaphor. We imaginatively project fronts and backs onto moving objects, and we conceptualize moving objects as facing in the direction of their motion (e.g., the front of the bus "faces" in the direction of its typical forward motion). Via the mapping of times as moving objects, times thus face the observer toward which they are moving, as in

"I can see the face of things to come. I can't face the future. Let's meet the future head-on."

Because the metaphorical motion of particular times is toward the observer, Time $\mathrm{B}$ can precede Time $\mathrm{C}$ and can follow Time A. This gives rise to expressions such as

"In the weeks following next Tuesday, nothing is scheduled. During the week preceding next Tuesday, things will be impossibly hectic. Wednesday follows Tuesday. Thursday comes after Wednesday. The preceding announcement was brought to you by Musicians for a Better World"

Moreover, because the present time is the time that is at the same location as the observer, we speak of the present redundantly as "here and now."

The second major metaphorical system for time involves a different spatial schema, one in which the observer moves across a landscape and times are points or regions on that landscape (see Table 2).

TABLE 1

The "MOVING TIMES"Metaphor

\begin{tabular}{lll}
\hline Source Domain (Space) & & Target Domain (Time) \\
\hline Objects & $\rightarrow$ & Times \\
Motion of objects past the observer & $\rightarrow$ & The "passage" of time \\
Location of the observer & $\rightarrow$ & The present \\
Space in front of the observer & $\rightarrow$ & The future \\
Space behind the observer & $\rightarrow$ & The past \\
\hline
\end{tabular}

Examples: The time will come when typewriters are obsolete. The days of inexpensive housing are long gone. The time for action has arrived. The deadline is fast approaching. Thanksgiving will be here before we know it. Christmas is coming, the goose is getting fat. The summer flew by. The time for end-of-summer sales has passed. 
TABLE 2

The "MOVING OBSERVER" Metaphor (Or "TIME'S LANDSCAPE')

\begin{tabular}{lll}
\hline Source Domain (Space) & & Target Domain (Time) \\
\hline Locations on observer's path & $\rightarrow$ & Times \\
Motion of the observer & $\rightarrow$ & "Passage" of time \\
Distance moved by observer & $\rightarrow$ & Amount of time "passed" \\
Location of the observer & $\rightarrow$ & The present \\
Space in front of the observer & $\rightarrow$ & The future \\
Space behind the observer & $\rightarrow$ & The past \\
\hline
\end{tabular}

Examples: I fear trouble up ahead. There's going to be profit for us down the noad. Will you be staying a long time or a short time? Let's spread the conference over two weeks. We're coming up on Christmas. He'll retire within two years. We're halfway through June already. We've reached the final week of the term.

The two vast metaphor systems, "MOVING TIMES" and "MOVING OBSERVER," define most of our spatialization of time. Notice that they are figure-ground reversals of one another. In the "MOVING TIMES" metaphor, the times are the figure moving relative to the stationary observer (as ground), whereas in the "MOVING OBSERVER" metaphor, the observer is the figure moving relative to the time landscape (as ground). Although the logic of each of these two metaphors is different, they both are based on the fundamental conception of the passage of time as relative spatial motion.

These two spatial metaphors for time both play a central role in our understanding of musical motion, to which we now turn.

\section{CONCEPTUAL METAPHOR AND MUSICAL. MOTION}

Our claim is that people have no robust way of conceptualizing musical motion without metaphor and that all reasoning about musical motion and musical space inherits the internal logic of such metaphors. If this claim is correct, and if the source domain for musical motion is motion in space, then the ways we learn about space and physical motion should be crucial to how we experience and think about musical motion. To see this, let us begin by considering three of the most important ways we experience and learn about motion:

(a) We see objects move. ${ }^{3}$

\footnotetext{
${ }^{3}$ For most people, our perception of moving objects is based principally on vision. However, other sensory modalities, such as the auditory system, give important information on motion. For blind people, for example, auditory cues play a critical role in determining direction, speed, and distance of moving objects.
} 
(b) We move our bodies.

(c) We feel our bodies being moved by forces.

Notice that all of these fundamental and pervasive experiences of motion are, for the most part, nonconceptual and prereflective, and yet they give rise to a large body of knowledge that we have about motion. For example, we experience objects and we experience ourselves moving from one point to another along some path, and so we develop our sense of locomotion (movement from one place [locus] to another). We experience moving objects changing speed through the application of physical forces. We know, in an immediate bodily way, what it feels like to be moved by something else and to move ourselves. It is this source-domain knowledge of physical motion that is carried over into the target domain (musical motion) via systematic metaphoric mappings.

Our central claim is that these three basic experiences of physical motion give rise, via metaphor, to three of the chief ways we conceptualize musical motion. Moreover, because musical motion, like physical motion, occurs over time, our two different metaphorical conceptualizations of time ("MOVING TIMES" and "TIME'S LANDSCAPE") are incorporated into the basic metaphors of musical motion. We examine each of these three types of experience of motion, along with the metaphors based on them.

\section{THE "MOVING MUSIC"METAPHOR}

"Here comes the recapitulation," "The strings slow down now," and "The music goes faster here." In this way we describe the metaphorical motion of a musical event as moving toward and then past us. According to this orientation, which incorporates the "MOVING TIMES" metaphor, a musical event is conceptualized as an object that moves past the stationary hearer from front to back. A future musical event-something that's "coming" in a piece of music we're listening to-exists in a musical space in front of the hearer and moves toward the hearer. When it reaches the stationary observer it is experienced (heard), because it now exists in the present moment. Once the musical event has occurred for us, it exists only in memory in the past, that is, in the metaphorical space behind the observer.

Because music is both a temporal and a tonal art, the "MOVING MUSIC" metaphor is a complex set of mappings that combine a notion of physical contours of motion with the "MOVING TIMES" metaphor, as shown in Table 3.

This mapping defines one of our most influential and pervasive ways of thinking about musical motion, as we import some of the logical entailments of the source domain into our experience of the target domain. Thus, the metaphorical logic of musical motion is based on the spatial logic of physical motion. To test this claim, we consider three of the most important kinds of inferences we draw about 
TABLE 3

The "MOVING MUSIC"Metaphor

\begin{tabular}{lll}
\hline Source (Physical Motion) & & \multicolumn{1}{c}{ Target (Music) } \\
\hline Physical object & $\rightarrow$ & Musical event \\
Physical motion & $\rightarrow$ & Musical motion \\
Speed of motion & $\rightarrow$ & Tempo \\
Location of observer & $\rightarrow$ & Present musical event \\
Objects in front of observer & $\rightarrow$ & Future musical events \\
Objects behind observer & $\rightarrow$ & Past musical events \\
Path of motion & $\rightarrow$ & Musical passage \\
Starting/ending point of motion & $\rightarrow$ & Beginning/end of passage \\
Temporary cessation of motion & $\rightarrow$ & Rest, caesura \\
Motion over same path again & $\rightarrow$ & Recapinulation, repeat \\
Physical forces (e.g., inertia, gravity, & $\rightarrow$ & "Musical forces" (c.g., inertia, \\
\multicolumn{1}{c}{ magnetism) } & & gravity, magnetism) \\
\hline
\end{tabular}

physical motion: (a) that motion requires an object that moves, (b) that motion will take place along a path, and (c) that motion will have a manner. We will then ask how those same structures of reasoning are present in our understanding of musical motion. ${ }^{4}$

First, physical motion requires an object that moves. Having observed that music "moves," we turn now to the something in the music that moves. The logic of physical motion (here, the fact that there must be something that moves) generates a corresponding question about music, namely, what is it that "moves" in music? This is a deeply perplexing and, we suggest, misleading question. When we speak of music in terms of the "MOVING MUSIC" metaphor, we mean that our experience of a bit of music shares something with our experience of seeing objects move in physical space. The metaphor leads us to speak as if there must be musical objects. Notice that we have this same problem in the "MOVING TIMES" metaphor, according to which we conceptualize times as moving objects, even though times are not objects in any physical sense.

Second, moving objects trace out an imaginary path of motion. In music, segments of a musical path are thus called passages.

The analysis that follows explores how our experieace and understanding of musical motion relies on our more basic experience and understanding of physical motion. The analysis begins with a relatively simple view of physical motion. Of course, a similar analysis could explore our concepts of physical motion and space. For example, Pedersen and colleagues (1998) argued that some concepts of space and orientation that we might expect to be universal are in fact culturally shaped in that they systematically reflect the structures of that culture's language. Such an exploration would further illuminate the ways in which metaphor structures all of our abstract concepts. But such an analysis lies beyond the scope of this article. 
Third, physical motion will have a manner. There will be something in the way the music moves. Objects can move quickly or slowly, abruptly or smoothly, forcefully or gently. Via the "MOVING MUSIC" metaphor, then, this same logic carries over into our understanding of the music as moving at some speed. That metaphorical speed is the tempo. We describe music as fast or slow. The "manner" of the motion is marked by words like "creep," "crawl," "rush," "fly," "slow down," "speed up," "walk," "float," "stumble," and so on. The music can proceed " by steps," or it can make "leaps" of various lengths. Virtually any concept of a particular manner of physical motion can be applied to music.

Notice that the word "way" is polysemous-it has multiple related meanings. "Way" can mean the literal path one takes to a destination (as in "The Roman legions marched along the Appian Way"). It can also mean the manner (metaphorically understood) in which something is done (as in "Play the piece this way, with vibrato"). Or it can mean the metaphorical path one takes to achieve an end (as in "That's the best way to solve this equation"). So, when we say, for example, "The tune goes this way," the "way" is the metaphorical path the music takes.

\section{THE "MUSICAL LANDSCAPE"METAPHOR}

A second basic experience of physical motion is our ability to move our bodies through a spatial landscape. We have the experience of moving from a starting point through a series of intermediate steps to a destination. Such experiences are the basis for a second major conception of a musical work, as an extended three-dimensional landscape through which the hearer moves. The listener takes a journey over the path that defines the particular piece of music being heard. Just as in the "TIME'S LANDSCAPE" metaphor the present moment is wherever the moving observer is, likewise in the music the present moment is where the listener is at a particular point along their journey. In other words, where the musical traveler is in the music-landscape is what the listener hears at that moment. Consequently, what has already been heard is conceptualized as points in the landscape that are behind the listener-traveler, whereas parts of the music not yet heard are future points on the path that one will encounter later. This explains expressions like the following:

"We're coming to the coda. When we get to measure 57 we'll see how the dissonance is resolved. Let's see, where are we in the second movement? The melody rises up ahead. At measure 4 the horns enter. Once you reach the refrain, the dissonant part is behind you. We're going faster here (said in reference to a point in the score). Two voices siart, but soon a third enters (joins in). The soloist is waiting to come in seven measures from here." 
Musical events are locations on a musical landscape, according to the conceptual mapping in Table 4 .

\section{TWO PERSPECTIVES: PARTICIPANT AND OBSERVER}

One can take two perspectives on the musical landscape: that of the participant and that of the observer. In the participant perspective you, the listener, are moving over the musical landscape. As listener, you are metaphorically in the piece, that is, you are traveling over the path that defines a particular musical piece, and you are actually hearing it (either in a live performance or on a recording). Imagine yourself, for example, listening to a Mozart string quartet and saying, "the cello comes in right here!" (where the word "here" is uttered just as the cello enters). The "here" is the place on the musical landscape where you are at the present moment. Notice also the strong tendency many people have to use a pointing gesture to accompany their uttering of the word "here," indicating the exact "location" at which the cello enters.

As you, the hearer, move through a musical space, you can stand in various spatial relations to different musical events (as locations) and you can notice various things along your journey. You can "approach the refrain, come to a resolution, look ahead to measure 21, pass the dissonant part, and see where the melody stops."

Within this landscape framework, repetition is tracing out the same trajectory of motion again. In music one can repeat the same path of motion, but always at a different time from the original musical event. However, the experience of tracing the same musical path over again is so powerful that it can actually make you feel as though you are experiencing the same time over again. Such metaphorically understood experiences are not limited only to music. We say, for example, "Oh no, it's Monday again," or "Here comes the weekend again!" with the sense that there is something about Monday (or the weekend) that is experienced as the same every

TABLE 4

The MUSICAL LANDSCAPE"Metaphor

\begin{tabular}{lll}
\hline Physical Space (Source) & & Musical Space (Target) \\
\hline Traveler & $\rightarrow$ & Listener \\
Path traversed & $\rightarrow$ & Musical work \\
Traveler's present location & $\rightarrow$ & Present musical event \\
Path aiready traveled & $\rightarrow$ & Music already heard \\
Path in front of traveler & $\rightarrow$ & Music not yet heard \\
Segments of the path & $\rightarrow$ & Elements of musical form \\
Speed of traveler's motion & $\rightarrow$ & Tempo \\
\hline
\end{tabular}


time it occurs. In music this effect appears to be even stronger. Some of the most striking effects in music come from its ability to make us feel like we're experiencing the same time over again, as though we are "back home" (and back now) again. 5

The second perspective on the musical landscape is an observer perspective. It is conceived as a distant standpoint from which you can observe the path through a musical landscape that defines a particular work. This is the perspective utilized most often by musicians who are analyzing a score. The score is one metaphorical representation of the imaginary path through an abstract musical space. Every expression that can be used when speaking from the participant perspective can also be used from the observer perspective, just as observers are traveling the musical journey in their imagination (in an imaginary space). The advantage that the allegedly "objective" observer perspective supplies is that one can see the entire musical piece at once, because it is an abstract object that can be viewed from afar. By contrast, from the participant perspective you ordinarily cannot see everything that is up ahead, because, according to the logic of the "MUSICAL LANDSCAPE" metaphor, from a particular standpoint within the music, you may not be able to see the entire path ahead.

The observer perspective on the musical landscape is typically the preferred metaphor for music analysis, because it allows one to treat the entire musical work as an abstract object and to study its features. Those features can supposedly be measured, analyzed, and looked at from various perspectives-precisely what the "objective" music theorist is regarded as doing.

We have argued that it is primarily our experience of seeing objects move that gives rise to the "MOVING MUSIC" metaphor and that it is primarily our experience of moving our own bodies from one place to another that gives rise to the "MUSICAL LANDSCAPE" metaphor.' Our central claim has been that it is the specific spatial logic of each particular source domain that controls the entailments of our metaphors of musical motion. For example, when music is viewed as a moving object, its status as metaphorical object gives it an aura of permanence. Also, taking the participant perspective within the "MUSICAL LANDSCAPE" introduces strong notions of intentional action within a piece of music. The music can "strive," "seek," "want to resolve," "push ahead," and so forth.

\footnotetext{
${ }^{5}$ The film Peggy Sue Gor Married (Coppola, 1986) draws powerfully on this desire we have to five through certain moments and experiences one more time-to be able to return to what bappened before and to relive it. In music, when you hear a certain motif once again, it may not merely be that sonething that occurred before is returning at a different time. Rather, you may feel that the same time is returning.

${ }^{6}$ Raymond Gibbs suggested that our experience of moving our own bodies may also provide a basis for the "MOVING MUSIC" metaphor. Although we do not deny this possibility, we have not found either polysemy or inferential evidence that supports this hypothesis.
} 
Another important entailment shared by both of the central metaphors we have discussed so far is that motions are shaped by forces. Whether we are experiencing the physical motion of our bodies or of other objects, we learn that the motion is influenced by physical "forces" like gravity, magnetism, and inertia. Recent work on "musical forces" makes this set of metaphorical entailments explicit. Arnheim (1986), Brower (1997-1998, 2000), Hurwitz (Hurwitz \& Larson, 1994), Larson (1993a, 1993b, 1994a, 1994b, 1997, 1997-1998, 1999, 2002, in press), Lerdahl (1996, 2001), Pelto (1994), and VanHandel (VanHandel \& Larson, 2000) used the idea of musical forces to illuminate issues of theory, analysis, cognition, and pedagogy.

Musical forces often pull us in different directions. But at one point in the Beatles" "Something," they all agree in a way that elegantly illustrates the meaning of the text "attracts me like no other lover." The line "Something in the way she moves" (Figure 2a, beginning) may be heard as an embellishment of the simpler, whole-note melody given in Figure $2 \mathrm{~b}$ (i.e., $\mathrm{a} \mathrm{C}-\mathrm{B}$ that begins a descending motion in half-steps).

Musical inertia, the tendency of a pattern to continue in the same fashion, suggests that this whole-note motion will continue descending in half steps, as in Figure $2 b$ (i.e., C-B-Bb-A). Musical gravity, the tendency of a melody to "descend," suggests that this whole-note motion will continue by going down. And musical magnetism, the tendency of an unstable pitch to resolve to the closest stable pitch, suggests that $\mathrm{Bb}$ will resolve to $\mathrm{A}$. Thus, all three musical forces here reinforce each other to powerfully "attract" the Bb of "attract" to the A of "lover."

a

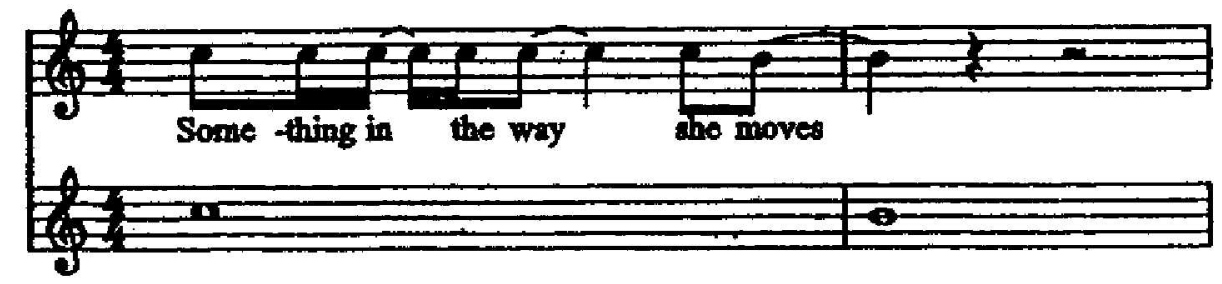

3.

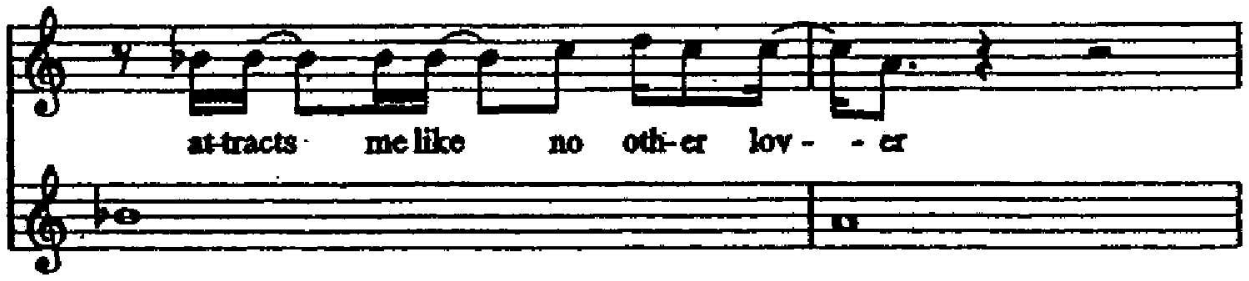

FIGURE 2 George Harrison, "Something," opening lyric compared to underlying whole-note melodic skeleton. 
TABLE 5

The "MUSIC AS MOVING FORCE" Metaphor

\begin{tabular}{lll}
\hline Source (Physical Motion) & & Target (Musical Experience) \\
\hline Locations & $\rightarrow$ & Emotional states \\
Movemeat (from place to place) & $\rightarrow$ & Change of emotional state \\
Physicai forces & $\rightarrow$ & Causes \\
Forced movement & $\rightarrow$ & Causation \\
Intensity of force & $\rightarrow$ & Intensity of musical impact \\
\hline
\end{tabular}

\section{THE “MUSIC AS MOVING FORCE"METAPHOR}

The third major way we experience physical motion is when physical substances and entities like wind, water, and large objects move us from one point to another (see Table 5). In music, the metaphorical force is the music itself, moving the hearer from one location (state) to another (different state). If music is a force, then it has causal effects. This idea of musical forces is thus a special case, via metaphorical extension, of what Lakoff and Johnson (1999) called the "LOCATION EVENT STRUCTURE" metaphor. According to the metaphor, "STATES ARE LOCATIONS," that is, metaphorical places that an entity can be "in" or "at," as when we say, "She was in a coma for three months," and "Jack is head over heals in love." Change of state is movement from one state-location to a different state-location, as in "The water went from hot to cold in five minutes," where the states of being "hot" or "cold" are metaphorical locations, and the water is hot when it occupies the "hot" location metaphorically and cold when it "moves" into the "cold" state-location. Causes of change are then metaphorical forces that move an entity from one location to another, as in "He fell into a depression, but therapy brought him out of it," "The psychological pressure drove me to drink," "Their taunting pushed me over the edge," and "I was forced to go in a different direction with my life." In short, "STATES ARE LOCATIONS," "CAUSES ARE PHYSICAL FORCES," and "CAUSATION IS FORCED MOTION" (from one state-location to another) ${ }^{7}$

Based on this generic metaphor for causation, musical forces are conceived as acting on listeners to move them from one state-location to another along some path of metaphorical motion. You can actually feel yourself being "pushed," "pulled," and generally "moved" by the music. When music is a "moving" experience, it can "bowl you over," "blow you away," "carry you along," "transport you," "give you a lift," and "take you on a roller coaster ride." It can make you "float along" or it can "drag you down." When the music "swings," you "swing."

\footnotetext{
${ }^{7}$ An extensive treatment of metaphors for events and causes is given in chapter 11 of Lakoff and Johnson (1999). Cox (1999) discussed musical instances of the "STATE ARE LOCATIONS" metaphor.
} 
"Something in the way she moves, attracts me like no other lover" can be as much about music as it is about love.

So when we say that "music moves" and that "music moves us," we do more than make a pun. This is another important instance of polysemy. Just as we pointed out previously that "way" has multiple metaphorically related senses, so too does "move" in its application to musical experience. The "MUSIC AS MOVING FORCE" metaphor helps to explain why we use the word "move" to mean these different, but related, things.

\section{OTHER METONYMIES AND METAPHORS FOR MUSICAL MOTION}

The three major ways of experiencing physical motion listed previously, on which three of our most important metaphors for musical motion are built, clearly do not exhaust our experience, knowledge, and conceptualization of motion. A comprehensive account would have to include additional metaphors and metonymies based on additional ways we experience motion and causation. Following are some additional metaphors that would need to be investigated as part of an exhaustive analysis. For example, the "MUSICAL LANDSCAPE" metaphor emphasizes only movement over a landscape. It does not focus explicitly on the cause of the motion. As with physical motion, I can either move myself (purposefully) over and through a landscape, or else I can be moved by forces beyond my control. These two different sources of motion will thus produce two different metaphoric scenarios, one in which "I move" over the landscape and the other in which "I am moved over the landscape." Thus, the "MUSIC AS MOVING FORCE" metaphor might actually be treated as one partial set of submappings of the "MUSICAL LANDSCAPE" metaphor. We have included it as a separate metaphor system because of the way it shows the embodied grounding in physical motion and also because it plays such a central role in our experience of music.

Other extensions and variations are possible too. Consider the way in which the metaphoric scenario in which "I move" through the musical landscape can be combined with the basic metonymy, the "PERFORMER IS THE MUSIC PERFORMED." The performer then creates the musical path as she moves. We can thus say to a performer, who is metonymically identified with the music she makes, "You speed up and go higher, just when she slows down and goes lower," "You've got to swing in the second movement," and "This is where you take over." Other extensions are also possible. Via the "INSTRUMENT FOR THE PERFORMER" metonymy, we can say "the horns rushed at measure 34," "the violins were sluggish," and "the drums got lost."

Another extremely important dimension, which we have only touched on here, involves our metaphorical conception of musical agency. In those metaphors 
where there is an agent who moves or is moved, such as in the "MUSICAL $\angle A N D S C A P E$ " metaphor, we can attribute intentions and purposes to the agent, and thereby to the music. We will then experience and understand music as purposive in various ways-as "going somewhere," "trying to resolve," "overcoming an obstacle," or "wanting to move to the dominant." Such purposive agency has been much discussed. ${ }^{8}$ We only observe here that our entire notion of agency is metaphorically shaped and that we cannot understand musical agency apart from one or more conceptual metaphors for event structure and causation.

\section{IS MUSICAL MOTION REAL?}

If most of what we can think and say about musical time and musical motion depends on metaphor and metonymy, then it might seem that there is no such thing as musical motion! Maybe it is just a fiction and a mere manner of speaking about music. Yet, we do seem to experience movement in music. So, is it real?

Our answer is that musical motion is just as real as temporal motion and just as completely defined by metaphor. "Music moves." We experience musical events as fast or slow, rising or falling, creeping or leaping, pausing and stopping. The reason that musical motion is "real" is that, as Hanslick (1986) said more than 150 years ago, music exists only in our "aural imagination," that is, only as experienced by us. Music is not the notes on the scores. Nor is it merely the vibrations of air that we hear as sounds. It is, rather, our whole vast rich experience of sounds synthesized by us into meaningful patterns that extend over time. This experience of musical motion is no less real for being a product of human imagination-which is our profound capacity to experience ordered, meaningful patterns of sensations. If

\footnotetext{
${ }^{8}$ See, for example, Maus (1997). Davies (1994) wrote that "as Cavell notes (1977), what is needed is an explanation of why we describe artworks in terms usually confined to the description of sentient creatures" (p. 151).

Writers on expressive meaning in music have long observed the relation between motion, emotion. and purpose. Davies (1994) surveyed several sources that describe music in such terms, tying our experience of musical motion to our experience of physical motion at more than one level. He noted that "musical movement invites attention to expressiveness because, like human action and behavior (and unlike random process), it displays order and purposiveness" (p. 229). This talk of musical movement as teleological brings into play-inevitably, we think-the metaphor of "MUSICAL FORCES:" "Usually musical movement is heard as teleological, as organized around a target that exercises a' $g r a v-$ itational pull' on other notes" (Davies, 1994, pp. 236-237).

"Clarke (n.d.) observed that music can give us clues about the motion of "fictional" or "virtual" sources. He argued that the sense of motion and gesture in music is a truly perceptual phenonenon, and that the perceptual information that specifies motion is broadly speaking the same as for the perception of motion in the everyday world" (p. xx). Although he claims that the experieace of musical motion "is neither real nor metaphorical," we believe that a close reading of his paper, rather than contradicting the arguments presented here, provides additional support for our argument. See also Gjerdingen (1994).
} 
there were no people like us, with bodies and brains like ours, then there would be no musical time and no musical motion. Music "exists" at the intersection of organized sounds with our sensory-motor apparatus, our bodies, our brains, our cultural values and practices, our music-historical conventions, our prior experiences, and a host of other social and cultural factors. Consequently, musical motion is really experienced by us, albeit via our imaginative structuring of sounds.

On the basis of the kinds of analyses and evidence given here, how strong a conclusion can we draw about the constitutive role of metaphor in our experience and understanding? The safer, although still controversial, claim is that our understanding and conceptualization of musical experience, and therefore our linguistic discourse about music, are in large measure irreducibly structured by deep conceptual metaphors. We are suggesting that there is a compelling body of empirical evidence for the correctness of this claim, some of which we have examined here.

However, we are inclined toward the even stronger, more polemical claim that our very experience of musical meaning is fundamentally shaped by conceptual metaphors that are grounded in our bodily experience. There can be no robust experience of musical meaning without these conceptual metaphorical framings and their spatial and bodily logics. We cannot clearly separate our understanding and conceptualization of music from our experience of it. We do not merely experience a musical work and then understand it. There is not experience first, followed by our grasp of the meaning of that experience. Rather, our understanding is woven into the fabric of our experience. Our understanding is our way of being in and making sense of our experience. Thus, the way we experience a piece of music will depend importantly on how we understand it, and our understanding is intimately tied to our embodiment, that is, to our sensory-motor capacities and to our emotional makeup. For example, we don't just listen to a musical passage that moves and then say "Hey, that piece really moves, and, by the way, I can see a similarity between the way the music moves and what happens when a person or object moves." If there were no physical motion, it is difficult to imagine how there could even be musical motion. It appears that you can experience musical motion only because of your embodied experience and your embodied understanding of physical motion.

\section{EMPIRICAL EVIDENCE}

The evidence we have given for the existence of at least three major metaphors for musical motion takes the following form: We show that people's bodily experience of, and reasoning about, various types of physical motion provides the basis for metaphors of musical events. Our account explains why we use the terms of space (and motion through space) for conceptualizing musical events, and it explains the inferences we make about musical motion. 
Recent work on "musical forces" offers some additional empirical support for the assertion that our experience of physical forces shapes our experience of musical motion. The evidence, to date, is of three kinds: (a) the distribution of patterns within compositions, improvisations, and analyses; (b) the behavior of computer models of melodic expectation; and (c) the responses of participants in psychological experiments.

As an example of the first sort of evidence, Larson (1997-1998) used his account of the musical forces of "gravity." "magnetism," and "inertia" to generate a small, well-defined set of three-, five-, and seven-note patterns in which the musical forces are best represented, and he found these patterns to be nearly identical with those discussed in published accounts of "hidden repetition" in tonal music. Larson (2002) considered all possible patterns that fill a third within the seventh chords of selected jazz compositions and transcribed jazz improvisations, and he found that the musical forces could account well for the distribution of those patterns within his analyses of those pieces.

As an example of computer models of melodic expectation, Larson's (1993a, 1994,1999 , in press) computer models rely on an algorithm that quantifies the interaction of musical forces, and he found that it-as well as Lerdahl's (1996) proposed revision of that algorithm - gave higher ratings to melodic continuations that were sung more often by participants in several different experiments.

Third, VanHandel and Larson (2000) found that the musical forces could account well for listeners' judgments about the experienced "strength" of presented pattern completions as well as the distribution of those same patterns within Schenker's Five Graphic Music Analyses (1932/1969).

Evidence in each of these forms provides some support for the theory of musical forces that is consistent with our hypothesis that metaphors for musical motion are grounded in experiences of physical forces and physical motion. But the ideas advanced here may suggest other hypotheses to be tested. Perhaps the approach described in Gibbs (1994) for priming studies could be used to test whether certain metaphorical entailments shape descriptions of musical experience.

\section{THE PLURALISTIC ONTOLOGY OF MUSICAL MOTION}

Another persistent worry about the idea that conceptual metaphors can be constitutive of our experience stems from the fact that typically there are multiple inconsistent metaphors for any given phenomenon. For example, in the "MOVING MUSIC" metaphor music moves and the perceiver is stationary, whereas in the "MUSICAL LANDSCAPE" metaphor the musical landscape is stationary and the perceiver moves over and through it. In the first case, musical events are objects that move, whereas in the second case they are locations on a musical landscape 
(and thus don't move). Consequently, we have two different and incompatible ontologies underlying these two different metaphors.

To some people, this inescapable inconsistency among various metaphorical structurings of our basic concepts for musical motion will be taken as evidence that the metaphors cannot really be constitutive and must rather be nothing but figures of speech.

On the contrary, we should begin by noting that what is true of musical motion is equally true of our incompatible conceptions of time and, generally, our inconsistent conceptions of a vast range of abstract concepts, including causation, morality, mind, self, love, ideas, thought, and knowledge. Our claim is that each of these different, and often inconsistent, metaphorical structurings of a concept gives us the different logics that we need to understand the richness and complexity of our experience. However strong our desire for a monolithic consistent ontology might be, the evidence does not support such a unified and simple view of human experience. The absence of any core literal concept of musical "events" should direct our attention to the ways we imaginatively conceive of the flow of our musical experience by means of multiple metaphors that provide the relevant logics of our various conceptions of musical motion and space. There is no more a single univocal notion of musical motion than there is of causation, and yet we have gotten along reasonably well by knowing when a specific metaphor for causation is appropriate within a specific context of inquiry.

The fact of multiple inconsistent metaphors for a single concept also sheds light on the important question of cultural difference and variation. The grounding of metaphors in bodily experience suggests possible universal structures (of bodily perception and movement) for understanding music. However, because there are multiple metaphors available, and because there may be differing cultural interpretations of bodily experience, metaphor provides one important avenue for exploring cultural and historical variation in significantly different conceptions of musical experience that might arise around the world.

\section{THE PRIMACY OF MUSICAL. MEANING}

We would like to end by highlighting one important insight that comes from an examination of the role of metaphor in our understanding and experience of music, namely that the mechanisms of human meaning extend far beyond the capacity for language. Philosophical reflection on music has often assumed that music is some kind of "language." There is a strong tendency among philosophers and music theorists to think that our "primary" experience of meaning is in language, so that whatever meaning music has must be measured against linguistic meaning. Moreover, these same theorists often adopt false views of linguistic meaning as tied solely to reference and to truth conditions. When music seems not to measure up to 
such mistaken referential criteria of linguistic meaning, it is then erroneously concluded that music is a second-class citizen of the intellectual world.

The problem here lies not so much in the idea of music as language, but rather in overly narrow and restricted views of linguistic meaning as involving objective reference that is alleged to be completely independent of the nature of our bodies. What is left out are the embodied and affective dimensions of linguistic and musical meaning alike. Music is meaningful in specific ways that some language cannot be, but it shares in the general embodiment of meaning that underlies all forms of symbolic expression, including gesture, body language, ritual, spoken words, visual communication, and so on. Thinking about how music moves us is not going to explain everything we need to know about language, but it is an excellent place to begin to understand how all meaning emerges in the flesh, blood, and bone of our embodied experience.

This brings us back, finally, to where we began-with the Beatles' music. We have already admired some of their text painting and its relation to musical motion. We would like to conclude by drawing your attention to another piece of text painting that emphasizes our point about the embodiment of musical meaning. The passage of music in Figure 3 resembles a common musical pattern known as a "sentence."

In a sentence, a short bit of music ("Idon't want to leave her now") is followed by a similar short bit of music ("You know I believe, and how"), which is then typically completed, and answered, by a longer, balancing unit. But here the balancing unit is stated only by the guitar alone. We expect a balancing unit of text to answer the two lines of text. In fact, we might expect words that will tell us, finally, what that "some-
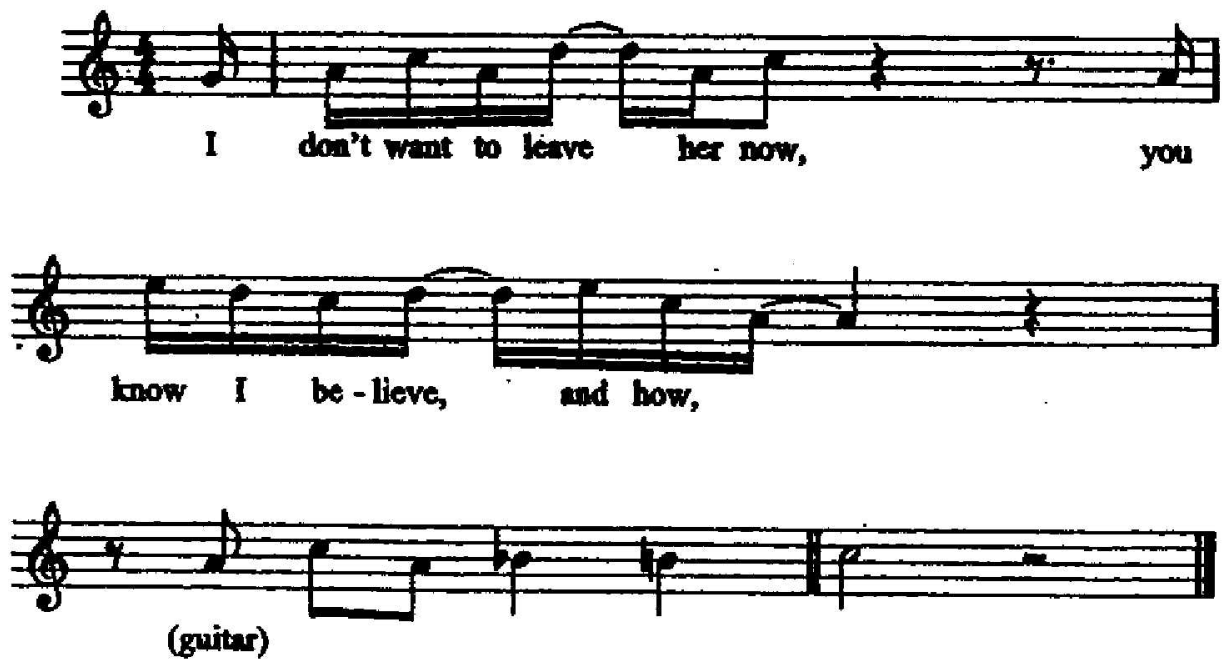

FIGUPE 3 George Harrison, "Something." guitar line ends verse. 
thing in the way she moves" actually is that "attracts me like no other lover." By giving us that balancing unit only in the guitar, without words, the Beatles seem to be saying that, in the end, only music can say what needs to be said. ${ }^{10}$ And they do it with a melodic line that not only retraces the path of what has gone before (the essential pitches of the guitar line, $\mathrm{A}-\mathrm{Bb}-\mathrm{B}-\mathrm{C}$, reverse the essential pitches of the opening lines of text--see the whole notes in Figure 2) but also leads us back to the beginning of the piece. Where the text leaves off, embodied musical meaning answers.

\section{ACKNOWLEDGMENTS}

We are indebted to Arnie Cox for his help with our analysis, which is the result of several months of collaborative work on the metaphorical understanding of musical experience (see his 1999 doctoral dissertation). We also thank our colleague, Scott Pratt, for his helpful comments on an earlier draft of this article. Earlier versions of this article were presented at the Conference on Musical Imagery sponsored by the University of Oslo, June 1999, and at the annual meeting of the West Coast Conference of Music Theory and Analysis in Eugene, April 2000.

\section{REFERENCES}

Aksnes, H. (1997). A cognitive approach to musical analysis: metaphorical projection in music. Proceedings of the Third Triential ESCOM Conference. Uppsata, Sweden.

Aksnes, H. (2000). Music and its resonating body. Dansk arbog for musickforskning (Danish yearbook for music research), Vol 29.

Alperson, P. (1980). "Musical time" and music as an "art of time." The Journal of Aesthetics and Art Criticism, 38, 407-417.

Amheim, R. (1986). Perceptual dynamics in musical expression. In New essays on the psychology of art (pp. 214-227). Berkeley: University of Califomia Press.

Baver, A. (in press). "Tone-color, movement, changing harmonic planes": Cognition, constraints and conceptual blends in modernist music. In A. Ashby (Ed.), Listening to modernism. Rochester: University of Rochester Press.

Bonds, M. E. (1992). Wordless rhetoric: Musical form and the metaphor of oration Cambridge, MA: Harvard University Press.

Brower, C. (1997-1998). Pathway, blockage, and containment. Theory and Practice, 22-23, 35-54.

Brower, C. (2000). A cognitive theory of musical meaning. Journal of Music Theory, 44, 323-379.

Clarke, E. (n.d.). Meaning and the specification of motion in music. Unpublished manuscript.

Coker, W. (1972). Music and meaning. New York: Free Press.

Coppola, F. F. (Director). (1986). Peggy Sue got married Motion Picture]. United States: Warner Bros.

\footnotetext{
${ }^{10}$ Everett (1999) reached a related conclusion about "Something" Although speaking of a different section of the song. Everett suggests that "the structural core of the song's melody, a fully supported $\wedge 3-\wedge^{\wedge} \wedge^{\wedge}$ descent heard only in the guitar solo, is best expressed in a musical fantasy. A poetic text here would only get in the way" (p. 25i).
} 
Cox, A. (1999). The metaphorical logic of musical motion and space. Unpublished doctoral dissertation, University of Oregon.

Cusick, S. G. (1994). Feminist theory, music theory, and the mind/body problem. Perspectives of New Music, 32, 8-27.

Davies, S. (1994). Mussical meaning and expression. Ithaca, NY: Cornell University Press.

Everett, W. (1999). The Bearles as musicians. New York: Oxford University Press.

Feld, S. (1981). "Flow like a waterfall": The metaphors of Kaluli musical theory. Yearbook For Tradirional Music, 13, $22-47$.

Ferguson, D. (1960). Music as metaphor: The elements of expression Minneapolis: University of Minnesota Press.

Gibbs, R. (1994). The poetics of mind: Figurative thought, language, and understanding. Cambridge, England: Cambridge University Press.

Gjerdingen, R. O. (1994). Apparent motion in music? Music Perception, 11, 335-370.

Graybill, R. (1990). Towards a pedagogy of gestural mythm. Journal of Music Theory Pedagogy, 4 , $1-50$.

Guck, M. (1981). Metaphors in musical discourse: The contribution of imagery to analysis. Unpublished doctoral dissertation, University of Michigan.

Guck, M. (1991). Two types of metaphoric transference. In J. Robinson (Ed), Music and meaning (pp. 201-212). Ithaca, NY: Correll.

Hanslick, E. (1986). On the musically beautiful (G. Payzant, Trans.). Indianapolis, IN: Hackett.

Harrison, G. (1969). Something. On Abbey road [CD]. London: Apple.

Hurwitz, R., \& Larson, S. (1994, October). Step collections in aural theory. Paper presented to a special panel on "Applying a Theory of Expressive Meaning in the Written- and Aural-Theory Classrooms" for the College Music Society.

Kassler, J. (Ed). (1991). Metaphor: A musical dimension. Sydney: Currency Press.

Lakoff, G., \& Johnson, M. (1999). Philosophy in the flesh: The embodied mind and its challenge to Westem thought. New York: Basic Books.

Larson, S. (1993a). Computer models of melodic continuation and key determination (CRCC Tech. Rep. 77). Paper presented to the Society for Music Perception and Cognition, Philadelphia. [Available from Center for Research on Concepts and Cognition; 510 North Fess; Bloomington, IN 47408]

Larson, S. (1993b). Scale-degree function: A theory of expressive meaning and its application to anral-skills pedagogy. Journal of Music Theory Pedagogy, 7, $69-84$.

Larson, S. (1994a). Another look at Schenker's counterpoint. Indiana Theory Review, 15, 35-52.

Larson, S. (1994b). Musical forces, step collections, tonal pitch space, and melodic expectation. In Proceedings of the Third International Conference on Music Perception and Cognition (pp. 227-229). Liege, Belgium.

Larson, S. (1997). The problem of prolongation in tonal music: Terminology, perception, and expressive meaning. Joumal of Music Theory, 41, 101-136.

Larson, S. (1997-1998). Musical forces and melodic patterns. Theory and Practice, 22-23, 55-71.

Larson, S. (1999). Swing and motive in three performances by Oscar Peterson. Jourmal of Music Theory, 43, 283-313.

Larson, S. (2002). Musical forces, melodic expectation, and jazz melody. Music Perception, 19. 351-385.

Larson, $S$. (in press). Musical forces and melodic expectation: Comparing computer models and experimental results. Music Perception.

Lerdahl, F. (1996). Calculating tonal tension. Music Perception, I3, 319-363.

Lerdahl, F. (2001). Tonal pitch space. New York: Oxford University Press.

Maus, F. E. (1997). Music as drama. In P. Robinson (Ed.), Ludwig van Beethoven: Fidelio (pp. 105-130). Cambridge, England: Cambridge University Press. 
McClary, S. (1991). Feminine endings: Music, gender, and sexuality. Minneapolis: University of Minnesota Press.

Mead, A. (1997-1998). Shedding scales: Understanding intervals in different musical contexts. Theory and Practice, 22-23, 73-94.

Mead, A. (1999). Physiological metaphors and musical understanding. Journal of Music Theory, 43. 1-19.

Morgan, R. (1980). Musical time/musical space. Critical Inquiry, 6, 527-538.

O'Donnell, S. (1999). Space, motion, and other musical metaphors. In R. Weiner (Ed.). Perspectives on

- the Grateful Dead: Critical writings (pp. 127-135). Westport, CT: Greenwood.

Pederson, E., Danziger, E., Levinson, S., Kita, S., Senft, G., \& Wilkins, D. (1998). Semantic typology and spatial conceptualization. Language, 74, 557-589.

Pelto, W. (1994, October). An alternative to rule memorization for written theory. Paper presented to a special panel on "Applying a Theory of Expressive Meaning in the Written- and Aural-Theory Classrooms" for the College Music Society.

Pierce, A. (1989). Spanning: Essays on music theory, performance, and movement. New York: Plenum.

Robinson, J. (1997). Music and meaning. Ithaca: Comeil University Press.

Rothfarb, L. (2001). Energetics. In T. Christensen (Ed.), The Cambridge history of western music theory (pp. 927-955). Cambridge, England: Cambridge University Press.

Saslaw, J. K. (1996). Fonces, containers, and paths: The role of body-derived image schemas in the conceptualization of music. Joumal of Music Theory, 40, 217-243.

Saslaw, J. K. (1997-1998). Life forces: Conceptual structures in Schenker's Free Composition and Schoenberg's The Musical Idea. Theory and Practice, 22-23, 17-33.

Saslaw, J. K., \& Walsh, J. P. (1996). Musical invariance as a cognitive structure: "Multiple meaning" in the early nineteenth century. In I. Bent (Ed.), Music theory in the age of romanticism (pp. 211-232). Cambridge, England: Cambridge University Press.

Schenker, H. (1932/1969). Five graphic music analysis (F. Salzer, Ed.). New York: Dover.

Van Handel, L., \& Larson, S. (2002). Measuring musical forces. Unpublished manuscript.

Zbikowski, L. (1997). Conceptual models and cross-domain mapping: New perspectives on theories of music and hierarchy. Jounal of Music Theory, 4I, 11-43.

Zbikowski, L. (1997-1998). Des Herzraums Abschied: Mark Johnson's theory of embodied knowledge and music theory. Theory and Practice, 22-23, 1-16.

Zbikowski, L. (1998). Metaphor and music theory: Reflections from cognitive science. Music Theory Online, 4.

Zuckerkandl, V. (1969). Sound and symbol: Music and the external world. Princeton, NI: Princeton University Press. 